\title{
Long non-coding RNA RFPL3S is a novel prognostic biomarker in lung cancer
}

\author{
ZHONGHUA LIU ${ }^{1,2^{*}}$, ZHIQIANG NING ${ }^{1,2^{*}}$, HAILIN LU ${ }^{1,2^{*}}$, TINGHUA CAO ${ }^{1,2}$, \\ FENG ZHOU ${ }^{3}, \mathrm{XIA} \mathrm{YE}^{3}$ and $\mathrm{CHAO} \mathrm{CHEN}^{1,2}$ \\ ${ }^{1}$ Department of Oncology, Suzhou Ninth People's Hospital; ${ }^{2}$ Department of Oncology, \\ The First People's Hospital of Wujiang District, Suzhou, Jiangsu 215200; ${ }^{3}$ Department of Oncology, \\ The First Affiliated Hospital of Soochow University, Suzhou, Jiangsu 215006, P.R. China
}

Received March 4, 2019; Accepted November 7, 2019

DOI: $10.3892 / \mathrm{ol} .2020 .11642$

\begin{abstract}
Long non-coding RNAs (lncRNAs) are functional components of the human genome. Recent studies have demonstrated that lncRNAs play essential roles in tumorigenesis, and are involved in cell proliferation, apoptosis, migration and invasion in several types of tumor, including lung cancer. However, the clinical relevance of IncRNA expression in lung cancer remains unknown. The aim of the present study was to investigate the expression pattern of RFPL3 antisense (RFPL3S) and its associations with clinicopathological characteristics in patients with lung cancer. Whether RFPL3S can act as a potential prognostic biomarker for lung cancer was also investigated. RFPL3S expression in tumor samples and cells was assessed using the Oncomine database and the Cancer Cell Line Encyclopedia, respectively. Based on Kaplan-Meier Plotter analyses, the prognostic values of RFPL3S were further evaluated. It was revealed that RFPL3S was highly expressed in lung cancer tissues when compared with normal tissues and was significantly associated with $\mathrm{pN}$ factor, pTNM stage and Ki-67 labeling index. In the survival analyses, increased RFPL3S expression was associated with poor survival and was inversely associated with first progression in all patients. These results
\end{abstract}

Correspondence to: Dr Chao Chen, Department of Oncology, Suzhou Ninth People's Hospital, 2666 Lu Dang Road, Suzhou, Jiangsu 215200, P.R. China

E-mail: hong0626@163.com

Dr Xia Ye, Department of Oncology, The First Affiliated Hospital of Soochow University, 188 Shi Zi Road, Suzhou, Jiangsu 215006, P.R. China

E-mail: 328757012@qq.com

*Contributed equally

Abbreviations: NSCLC, non-small cell lung cancer; lncRNA, long non-coding RNA; SCLC, small-cell lung cancer; RFPL3S, RFPL3 antisense; lncRNA, long non-coding RNA; OS, overall survival; PPS, post-progression survival; FP, first progression

Key words: lung cancer, lncRNA, RFPL3S, biomarker, prognosis indicate that RFPL3S may be of clinical significance and may act as a prognostic biomarker in lung cancer.

\section{Introduction}

Lung cancer is the most common cause of cancer-associated mortalities worldwide, accounting for one in four mortalities and the incidence rate was 96.8 per 100,000 in 2008 in the United States (1). It is estimated that $2,093,876$ new cases are diagnosed annually around the world and the 5-year survival rate for patients with lung cancer is $18 \%$, which is the lowest among the major types of cancer, including breast, colon and liver cancer (1). Non-small cell lung cancer (NSCLC) and small cell lung cancer (SCLC) account for 85 and $15 \%$ of all lung cancer cases (2), respectively. The former subgroup is typically comprised of two common subtypes, adenocarcinoma ( 70\%) and squamous cell lung cancer ( $30 \%)$ (2). The mechanisms underlying lung carcinogenesis are complex and poorly understood. Numerous cellular phenomena, including hypoxia, inflammation, the tumor microenvironment and oxidative stress, coupled with various molecular events, promote lung cancer initiation and progression (3-6). The majority of patients with lung cancer have a poor prognosis due to recurrence and distant metastasis $(7,8)$. Despite the advancements in chemotherapy, radiotherapy and surgical techniques for lung cancer in recent years, the long-time survival rate has failed to improve (9). The lack of appropriate molecular biomarkers is one of the main reasons for this failure as it results in patients being diagnosed at an advanced or distant metastatic stage, at which point curative treatments are no longer available $(10,11)$. For patients with lung cancer, diagnosis and treatment at an early stage of disease can prolong survival (12). At present, the clinical diagnosis of lung cancer depends on chest X-ray and low dose computed tomography scans (13); however, the high false positive rates (14), side-effects of radiation and the high costs may influence diagnostic accuracy and limit utility in lung cancer screening. In addition, approaches such as bronchoscopy and biopsy can be used, but they are painful, invasive and laborious (15). As a result, it is imperative to identify novel, sensitive and reliable biomarkers, as well as more efficient therapeutic targets to improve the diagnosis and treatment of patients with lung cancer. 
The whole human genome consists of 20,000-25,000 genes; however, only $2 \%$ of genome sequences encode proteins (16) and at least $90 \%$ of human genes are transcribed into non-coding RNAs (ncRNAs) (17). Currently, several ncRNAs have been discovered, including ribosomal RNAs, transfer RNAs, piwi-interacting RNAs, microRNAs and long non-coding RNAs (lncRNAs), which were previously regarded as useless, but they are now known to have crucial biological functions (18). According to transcript size, the remaining ncRNAs are classified into small ncRNAs $(<200 \mathrm{nt})$ and lncRNAs (>200 nt) (13). lncRNAs can be classified into the following 6 categories: Sense, antisense, divergent, bidirectional, intronic and intergenic (19). IncRNAs have attracted the most attention and an increasing number of studies have demonstrated that many lncRNAs play crucial regulatory roles in a wide variety of physiological processes, including development, differentiation and metabolism at the transcriptional, post-transcriptional and epigenetic levels $(20,21)$. At the transcriptional level, lncRNAs regulate gene expression depending upon the sequence and relative position; for example, by combining with the promoters of target genes and forming stable DNA-RNA triplex complexes to inhibit transcription initiation (22). At the post-transcriptional level, a number of lncRNAs may competitively bind to the target mRNA and prevent the binding of transcription factors, resulting in aberrant mRNA translation, splicing and degradation (23). At the epigenetic level, IncRNAs promote chromatin reprogramming genome-wide and regulate DNA methylation (24) and histone modification $(25,26)$. Genome-scale approaches revealed that several lncRNAs have a significant secondary structure (24), which is critical to specific binding and function (27), and shares certain common sequence features, including paucity of introns, low GC content, weak start codon and open reading frame contexts (28). Aberrantly expressed lncRNAs in various types of cancer are thought to contribute to tumorigenesis by influencing tumor cell proliferation, resisting cell death, enabling distant metastasis and replicative immortality, and inducing angiogenesis (20,29-32). However, the roles of lncRNAs in lung cancer and their association with clinicopathological parameters remain largely unknown and therefore require further study.

The RFPL3 antisense (RFPL3S) gene is located on chr22:32,359,906-32,382,052 (GRCh38/hg38) and has been suggested to regulate the sense RFPL genes at the post-transcriptional level (33). RFPL3S consists of eight transcripts with a length range between 334 and 1,295 bp (33). The present study further investigated the expression of RFPL3S in lung cancer based on tissue samples and databases, with the purpose of investigating the prognostic implications and expression pattern of RFPL3S, as well as the associations with clinicopathological characteristics in patients with lung cancer.

\section{Materials and methods}

Tissue specimens. Human lung cancer tissue samples and adjacent non-cancerous tissues (within $3 \mathrm{~cm}$ of cancer tissue) were obtained from 205 patients who underwent surgical resection of lung cancer between January 2009 and October 2011 at The First People's Hospital of Wujiang District (Suzhou, China). Written informed consent was obtained from all patients and the present study was approved by the Ethics
Committee of the First People's Hospital of Wujiang District. The collected tissue samples were frozen in liquid nitrogen until subsequent analysis. None of the patients had received any therapy, including chemotherapy and radiotherapy, prior to surgery. The histological grades were classified according to the World Health Organization guidelines (34) and the tumors were staged using the 7 th edition of the tumor-node-metastasis (TNM) staging system (35).

Reverse transcription-quantitative $(R T-q) P C R$ analysis. Total RNA was extracted from tissues using TRIzol ${ }^{\circledR}$ reagent (Invitrogen; Thermo Fisher Scientific, Inc.), according to the manufacturer's protocol. cDNA was synthesized with $1 \mu \mathrm{g}$ total RNA using the Primer Script RT mix (Takara Biotechnology Co., Ltd.). qPCR analysis was subsequently performed with the SYBR Green Real-time PCR Master Mix (Takara Biotechnology Co., Ltd.) in a $20 \mu \mathrm{l}$ reaction volume. The thermocycling conditions were as follows: $95^{\circ} \mathrm{C}$ for $20 \mathrm{sec}$ (pre-denaturation), followed by 40 cycles of $95^{\circ} \mathrm{C}$ for $10 \mathrm{sec}$ (denaturation) and $60^{\circ} \mathrm{C}$ for $45 \mathrm{sec}$ (extension). The primers were designed using Primer Premier software (version 5.0; Premier Biosoft International) and the sequences were as follows: RFPL3S forward 5'-GTC GTCAGAAATGAGGAGGAAGT-3' and reverse, 5'-TTGAAG TAGAAGAGAGGCATGGG-3' and GAPDH forward, 5'-CAA GGTCATCCATGACAACTTTG-3' and reverse, 5'-GTCCAC CACCCTGTTGCTGTAG-3'. The relative gene expression levels were calculated using the $2^{-\Delta \Delta C q}$ method (36) and normalized to the internal reference gene GAPDH. Each sample was run in triplicate and independently repeated three times.

Immunohistochemistry. Tissue blocks were cut into 5- $\mu \mathrm{m}$ thick sections and prepared for immunohistochemical staining. The sections were deparaffinized and rehydrated using a graded series of alcohol solutions, according to standard protocols. Endogenous peroxidase activity was blocked by incubating the sections with $3 \%$ hydrogen peroxide in methanol for $30 \mathrm{~min}$ at room temperature. For antigen retrieval, the sections were placed in $10 \mathrm{mM}$ citrate buffer ( $\mathrm{pH} \mathrm{6.0)}$ for $20 \mathrm{~min}$ at $95^{\circ} \mathrm{C}$. Sections were blocked with 5\% BSA (Dako; Agilent Technologies, Inc.) for $30 \mathrm{~min}$ at room temperature, in order to inhibit non-specific binding. Subsequently, the sections were incubated in a humidified chamber for $1 \mathrm{~h}$ at room temperature with primary antibody directed against Ki-67 (1:50; cat.no. MA5-14520; Thermo Fisher Scientific, Inc.). After washing three times with ice-cold PBS, the sections were incubated with a biotinylated goat anti-rabbit antibody secondary antibody (1:1,000; cat. no. RS0002; Dako; Agilent Technologies, Inc.) for $30 \mathrm{~min}$ at room temperature. The DAB Elite kit (Dako; Agilent Technologies, Inc.) was employed to visualize peroxidase activity and the sections were counterstained with Mayer hematoxylin for $1 \mathrm{~min}$ at room temperature, followed by dehydration and mounting. The expression of Ki-67 was evaluated using the labeling index, which was determined by counting 500-1,000 tumor cells under a light microscope (magnification, $x 400$ ). Tumor cells with $\geq 31 \%$ Ki-67 staining were defined as high $\mathrm{Ki}-67$, based on the median value of positive staining. All sections were independently and blindly evaluated by three pathologists, one from the Department of Oncology, Suzhou Ninth People's Hospital and two from the Department of Oncology, The First Affiliated Hospital of Soochow University (both Suzhou, China). The average of the 
scores from the three independent pathologists was the final immunohistochemical score.

Oncomine analysis. RFPL3S mRNA levels in different types of cancer were determined using the Oncomine database (www.oncomine.org), which is a publicly accessible online cancer microarray database that facilitates genome-wide expression analyses (37). In the present study, the unpaired student's t-test was used to generate a P-value for comparison between the tumor and adjacent non-cancerous tissues. The fold change was defined as 2 and the P-value was set at 0.01 .

Cancer Cell Line Encyclopedia (CCLE) analysis. RFPL3S mRNA levels in lung cancer were analyzed using the CCLE database (portals.broadinstitute.org/ccle/home), which is an online encyclopedia that facilitates the identification of genetic, lineage and predictors of drug sensitivity (37).

Kaplan-Meier plotter survival analysis. The prognostic values of lung cancer samples with high RFPL3S expression were further assessed using the Kaplan-Meier plotter (kmplot. com/analysis).

Statistical analysis. Statistical analyses were performed using SPSS software (version 18.0; IBM Corp.) and GraphPad Prism (version 6; GraphPad Software, Inc.). The prognostic impacts of RFPL3S were estimated using the Kaplan-Meier method and survival curves were compared using the log-rank test. The associations between clinicopathological characteristics and RFPL3S expression were analyzed by the $\chi^{2}$ test. The data on RFPL3S expression in paired tumor tissue samples and adjacent non-cancerous tissues were analyzed via the paired Student's t-test. $\mathrm{P}<0.05$ was considered to indicate a statistically significant difference and the data are presented as the mean \pm standard deviation.

\section{Results}

Association between RFPL3S expression levels and clinicopathological characteristics. The present study investigated the association between RFPL3S expression levels and clinicopathological characteristics, including sex, age, smoking history, differentiation, histological type, pT factor, pN factor, pTNM stage and Ki-67 labeling index in patients with lung cancer (Table I). A total of 42 female and 163 male patients with a median age of 64 years (range, 30-86 years) were subdivided into the following two groups based on their RFPL3S expression levels, high expression ( $n=149$ patients) and low expression ( $n=56$ patients). For the lung cancer samples, increased RFPL3S expression was more frequently observed in well- and moderately-differentiated tumors than in poorly-differentiated tumors $(\mathrm{P}=0.0229)$. In addition, it was noted that RFPL3S expression was significantly associated with $\mathrm{pN}$ factor $(\mathrm{P}=0.0267)$, pTNM stage $(\mathrm{P}=0.0117)$ and Ki-67 labeling index $(\mathrm{P}<0.0001)$; however, no significant associations were demonstrated between RFPL3S expression and sex $(\mathrm{P}=0.5672)$, age $(\mathrm{P}=0.2603)$, smoking history $(\mathrm{P}=0.3432)$, histological type $(\mathrm{P}=0.3995)$ or $\mathrm{pT}$ factor $(\mathrm{P}=0.0513)$ (Table I). These results demonstrate that increased RFPL3S expression levels tend to be associated with poorer
Table I. Associations between RFPL3S expression levels and clinicopathological characteristics in patients with lung cancer.

\begin{tabular}{|c|c|c|c|c|}
\hline \multirow[b]{2}{*}{ Characteristics } & \multirow[b]{2}{*}{ Patient, $\mathrm{n}$} & \multicolumn{2}{|c|}{$\begin{array}{c}\text { RFPL3S } \\
\text { expression }\end{array}$} & \multirow[b]{2}{*}{ P-value } \\
\hline & & High & Low & \\
\hline Sex & & & & 0.5672 \\
\hline Male & 163 & 117 & 46 & \\
\hline Female & 42 & 32 & 10 & \\
\hline Age, years & & & & 0.2603 \\
\hline$<60$ & 101 & 77 & 24 & \\
\hline$\geq 60$ & 104 & 72 & 32 & \\
\hline Smoking history & & & & 0.3432 \\
\hline Smoker & 142 & 106 & 36 & \\
\hline Non-smoker & 63 & 43 & 20 & \\
\hline Differentiation & & & & 0.0229 \\
\hline Well + Moderate & 140 & 95 & 45 & \\
\hline Poor & 65 & 54 & 11 & \\
\hline Histological type & & & & 0.3995 \\
\hline Squamous & 111 & 78 & 33 & \\
\hline Adenocarcinoma & 94 & 71 & 23 & \\
\hline pT factor & & & & 0.0513 \\
\hline $\mathrm{T} 1-2$ & 148 & 102 & 46 & \\
\hline $\mathrm{T} 3-4$ & 57 & 47 & 10 & \\
\hline $\mathrm{pN}$ factor & & & & 0.0267 \\
\hline No & 95 & 62 & 33 & \\
\hline $\mathrm{N} 1-2$ & 110 & 87 & 23 & \\
\hline pTNM stage & & & & 0.0117 \\
\hline I-II & 137 & 92 & 45 & \\
\hline III-IV & 68 & 57 & 11 & \\
\hline $\mathrm{Ki}-67$ labeling index & & & & $<0.0001$ \\
\hline$<31$ & 98 & 54 & 44 & \\
\hline$\geq 31$ & 107 & 95 & 12 & \\
\hline
\end{tabular}

RFPL3S, RFPL3 antisense; TNM, tumor-node-metastasis.

differentiation, lymph node metastasis, TNM stage and Ki-67 labeling index.

RFPL3S is upregulated in lung cancer. Based on the Oncomine analysis, no significant differences were demonstrated in the 56 total unique analysis when cancer tissues were compared with normal tissues (Fig. 1A). The outlier analysis, used to determine significant RFPL3S expression in a subset of the patient samples, suggested that there were eight cases with a significant increase and three with a significant decrease in RFPL3S expression. Patients with a significant increase included two patients with breast cancer and one patient with brain and CNS cancer (Fig. 1A). In the present study, RFPL3S was found in several types of human cancers including sarcoma, leukemia, breast, head and neck, lung and prostate cancer based on the Oncomine analysis, and significantly increased RFPL3S levels were detected 
A

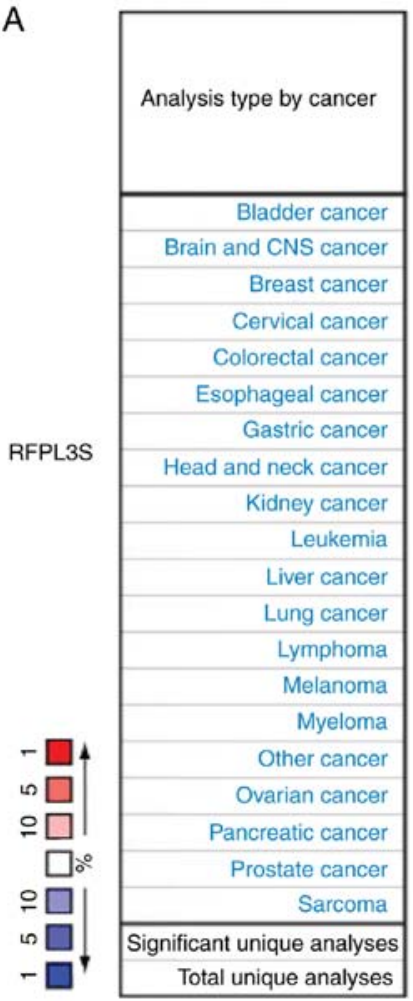

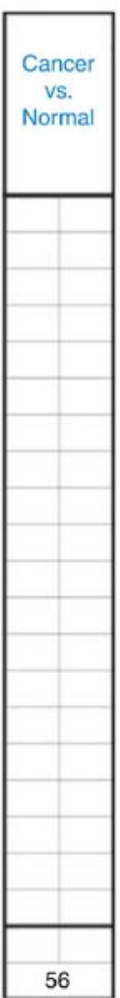

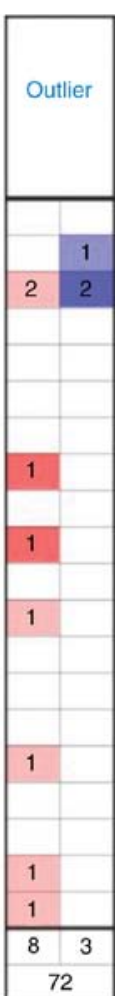

B

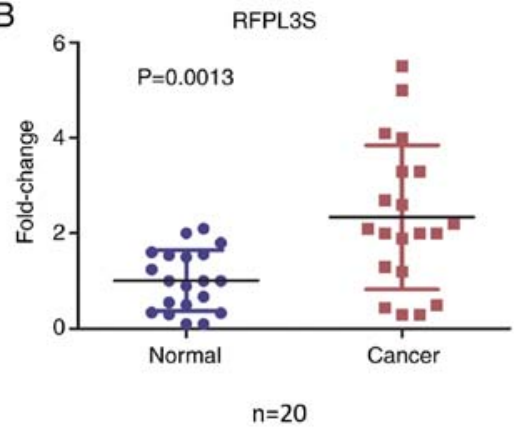

Figure 1. Expression of RFPL3S both in Oncomine and lung cancer tissues. (A) The Oncomine database revealed statistically significant RFPL3S expression levels. Red and blue represent RFPL3S upregulation and downregulation, respectively. The threshold was $\mathrm{P}=0.01$ and the fold-change was 2 . The gene rank was analyzed based on the percentile of target lncRNAs. The outlier analysis, which was used to determine significant RFPL3S expression, represents a small subset of samples within the datasets. (B) Expression levels of RFPL3S in lung cancer tissues and their adjacent non-cancerous tissues. RFPL3S, RFPL3 antisense.

mRNA expression (RNAseq): RFPL3S

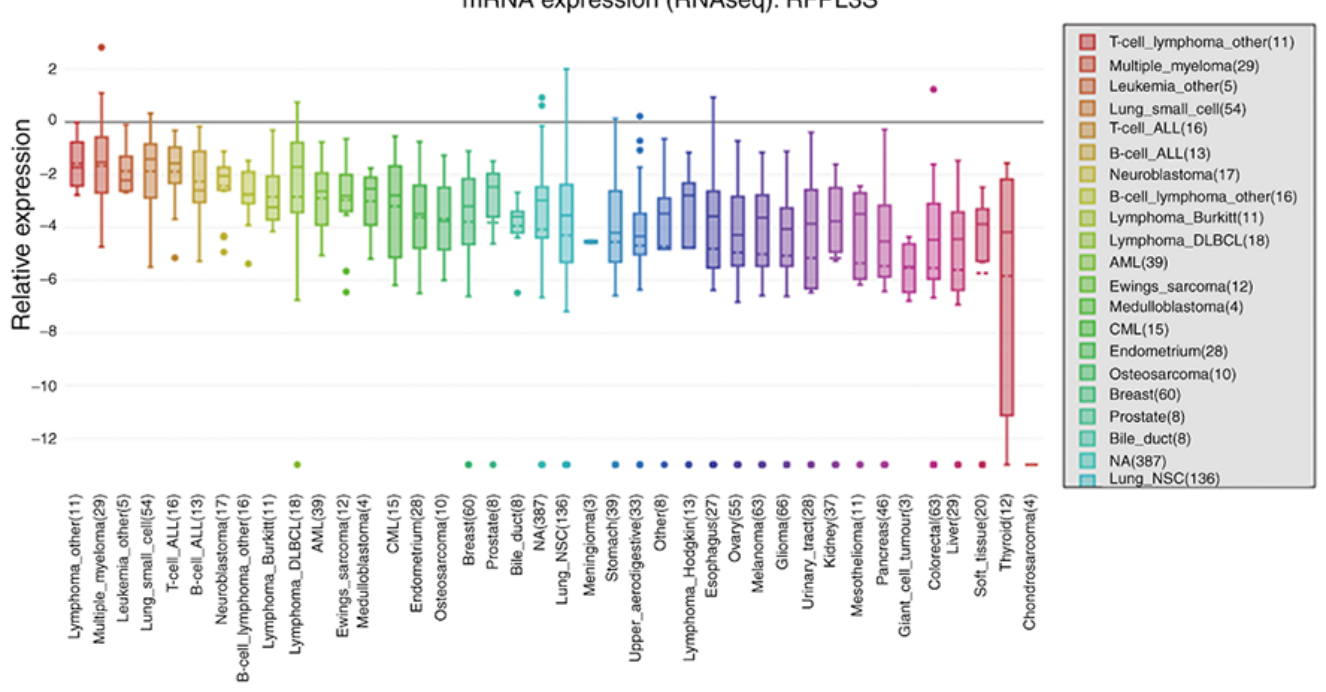

Figure 2. Level of RFPL3S mRNA expression on a logarithmic scale in various cancer types as determined by Cancer Cell Line Encyclopedia analysis. RFPL3S in lung cancer ranked the fourth highest in a variety of different cancer cell lines RFPL3S, RFPL3 antisense.

in leukemia and head and neck cancer. Furthermore, the present study determined the levels of RFPL3S expression in 20 pairs of lung cancer tissues and adjacent non-cancerous tissues and revealed that RFPL3S transcripts were 2.683 -fold higher in lung cancer samples compared with normal tissues ( $\mathrm{P}=0.0013$; Fig. 1B).

In addition, the mRNA expression of RFPL3S in different cancer cell lines was obtained via CCLE analysis
(Fig. 2). In line with the results of the Oncomine analysis, the expression levels of RFPL3S were demonstrated to be upregulated in lung cancer cell lines compared with normal cell lines, including SCLC and NSCLC cell lines, and ranked the fourth highest in SCLC cell lines among the different types of cancer. Notably, RFPL3S mRNA expression levels ranked the third highest in leukemia cell lines, behind that of lymphoma and multiple myeloma, and are also observed 
A

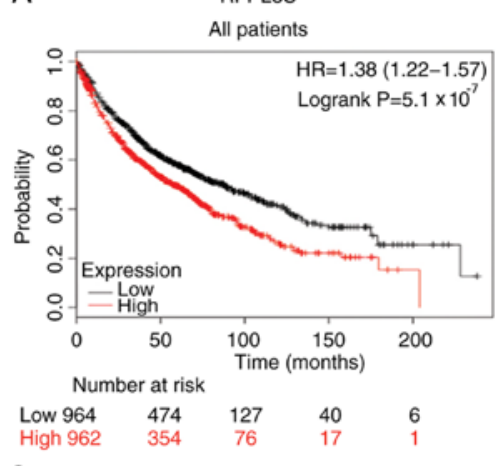

C Squamous cell carcinoma

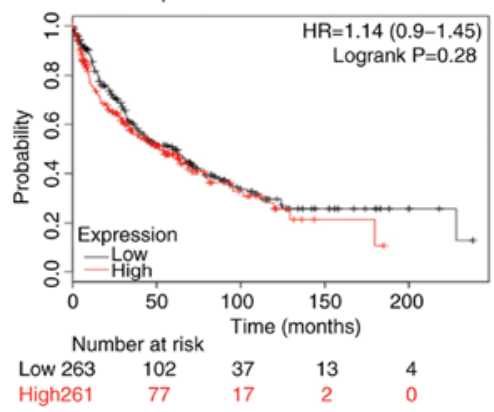

E

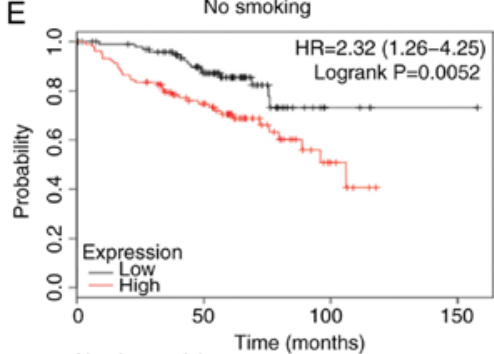

\begin{tabular}{lrrr}
\multicolumn{4}{c}{ Number at risk } \\
Low 102 & 65 & 3 & 1
\end{tabular}

G

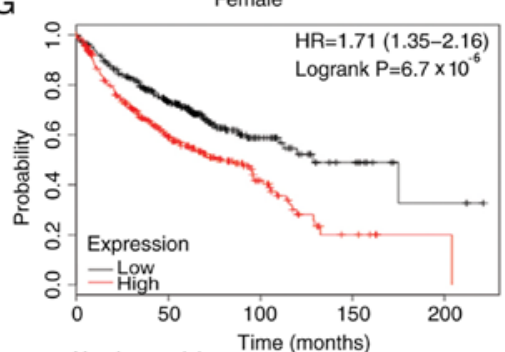

Number at risk Time (months)

$\begin{array}{lc} & \text { Number at risk } \\ \text { Low } 360 & 208 \\ \text { High } 355 & 144\end{array}$

1. Stage 1

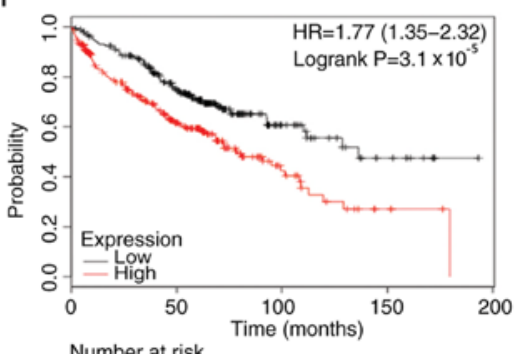

Number at risk

Low $292 \quad 182$
B
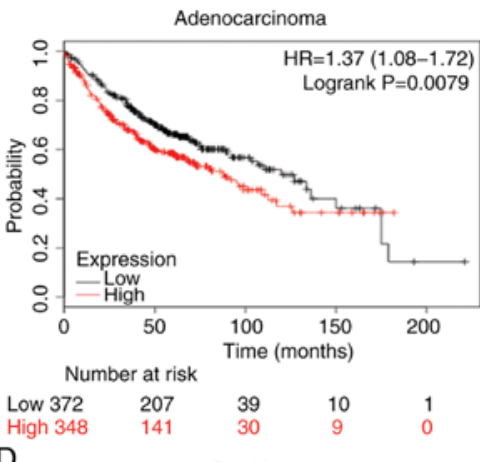

D
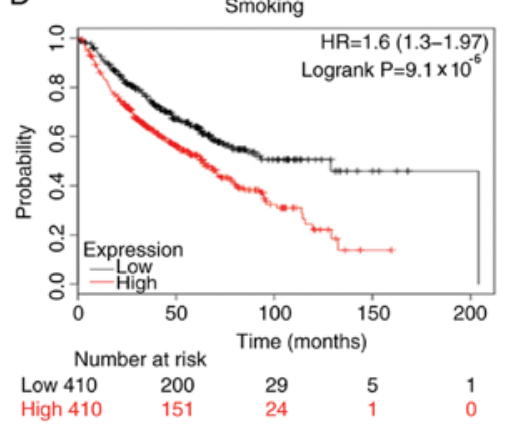

$\mathrm{F}$

Surgical margins negative

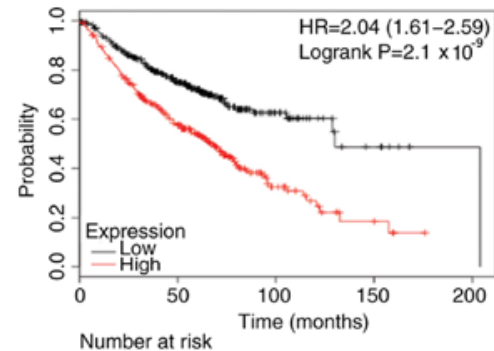

$\begin{array}{lllll}\text { Low } 364 & 198 & 32 & 6 & 1 \\ \text { High } 362 & 167 & 24 & 5 & 0\end{array}$

$\mathrm{H} \quad$ Male

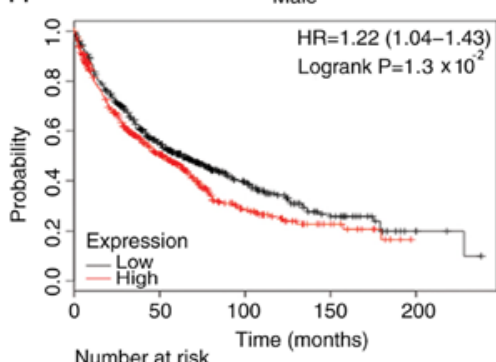

$\begin{array}{ccccc}\text { Number at risk } & & & \\ \text { Low } 559 & 255 & 82 & 27 & 4 \\ \text { High } 541 & 195 & 49 & 14 & 0\end{array}$

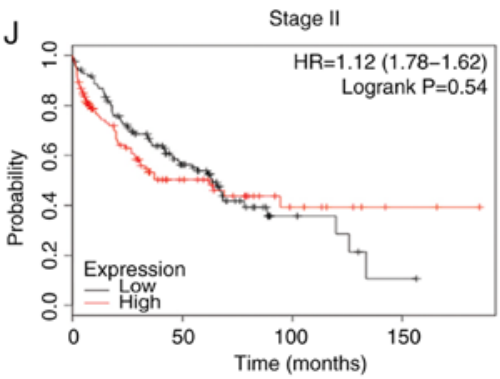

Number at risk

Low 123

High 121

Figure 3. Kaplan-Meier survival curves of patients with lung cancer stratified by expression levels of RPFL3S. Black and red lines indicate patients with low or high RFPL3S expression, respectively. Overall survival analysis of RFPL3S expression in lung cancer in (A) all patients, (B) adenocarcinoma, (C) squamous cell carcinoma, (D) smokers, (E) non-smokers, (F) tumor-negative surgical margins, (G) females, (H) males, (I) stage I and (J) stage II. Statistical significance was calculated using the log-rank test. RFPL3S, RFPL3 antisense. 
A

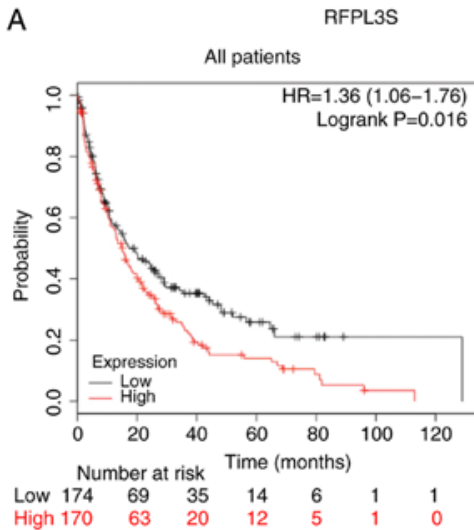

C

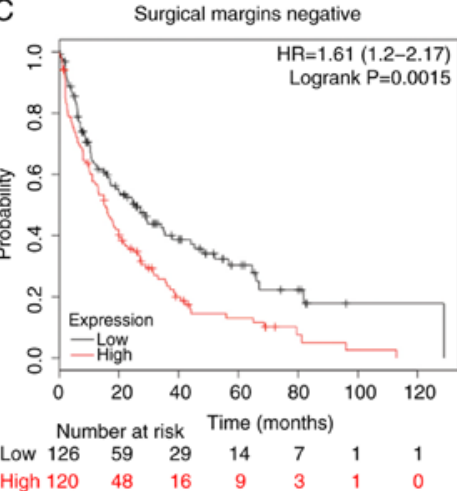

E

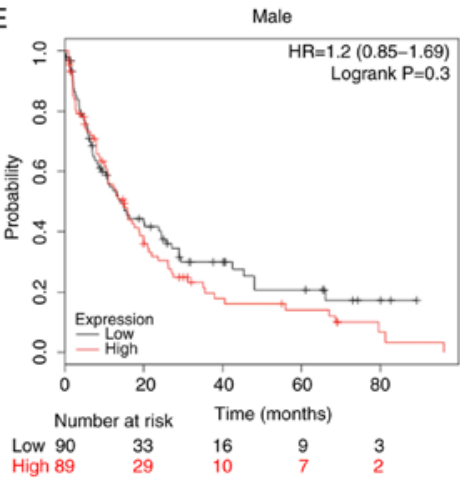

Post-progression survival

B Adenocarcinoma

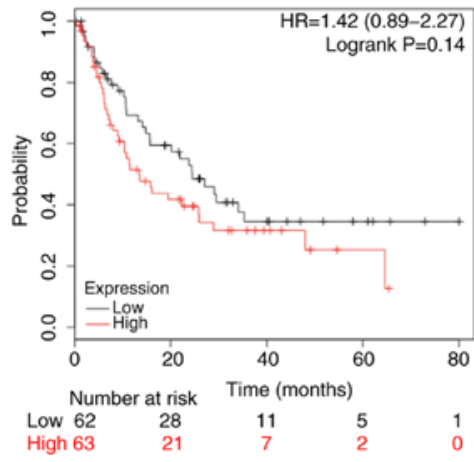

D

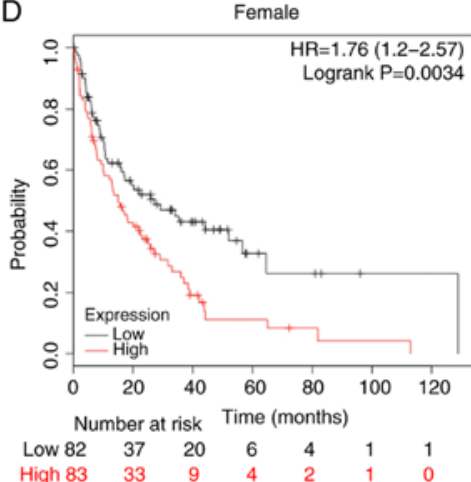

F $\quad$ No radiotherapy

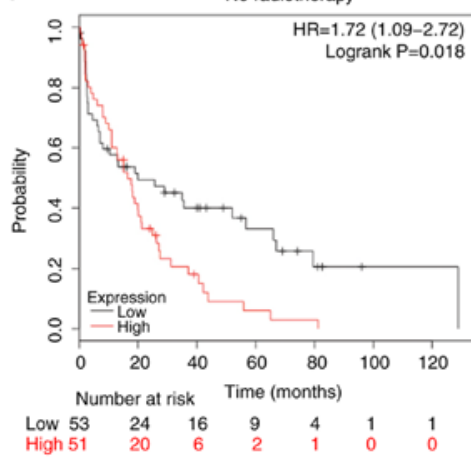

G

Radiotherapy

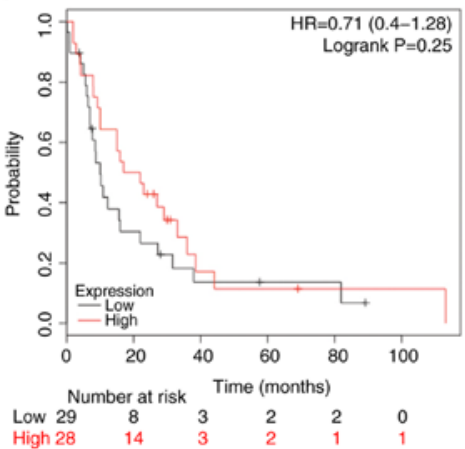

Figure 4. Kaplan-Meier survival curves of patients with lung cancer stratified by expression levels of RPFL3S. Black and red lines indicate patients with low or high RFPL3S expression, respectively. Post-progression survival analysis of RFPL3S in lung cancer in (A) all patients, (B) adenocarcinoma, (C) tumor-negative surgical margins, (D) females, (E) males, (F) patients who received radiotherapy and (G) patients who did not receive radiotherapy. Statistical significance was calculated using the log-rank test. RFPL3S, RFPL3 antisense.

in breast and prostate cancer, which was consistent with the results of the Oncomine analysis. These results indicate that RFPL3S may play unique roles in the development of several types of cancer.
Association between RFPL3S expression and survival in patients with lung cancer. Since RFPL3S was revealed to be highly expressed in lung cancer, the present study further investigated the potential prognostic roles of RFPL3S in lung 
A
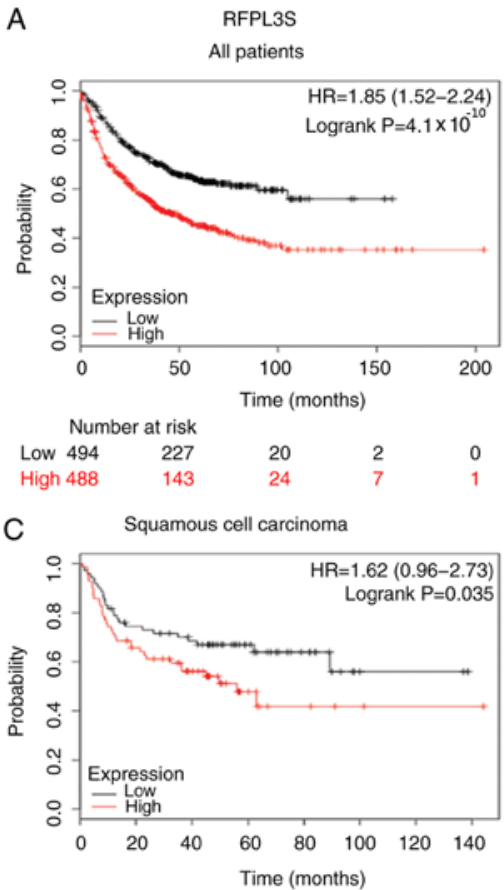

Number at risk

$\begin{array}{llllclll}\text { Low 71 } & 51 & 44 & 24 & 12 & 3 & 2 & 0 \\ \text { High 70 } & 44 & 30 & 10 & 4 & 2 & 1 & 1\end{array}$

E

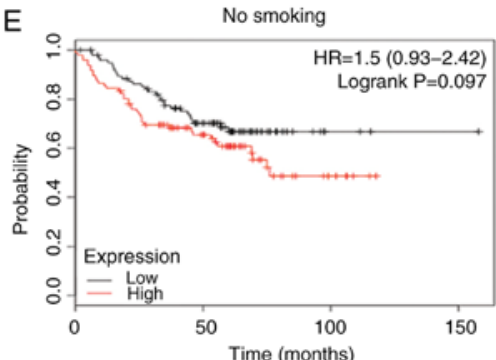

Number at risk

$\begin{array}{ll}\text { Low } 97 & 53 \\ \text { High } 96 & 45\end{array}$

G

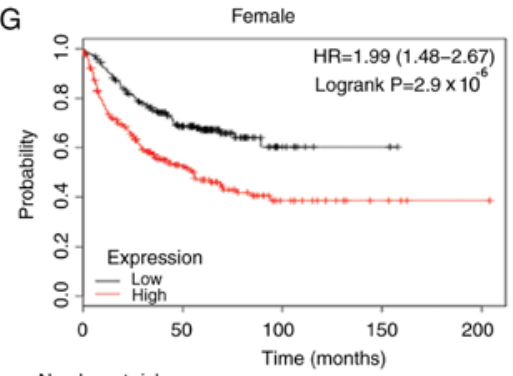

Number at risk

$\begin{array}{rrrrr}\text { Low 236 } & 118 & 9 & 2 & 0 \\ \text { High 232 } & 75 & 15 & 4 & 1\end{array}$

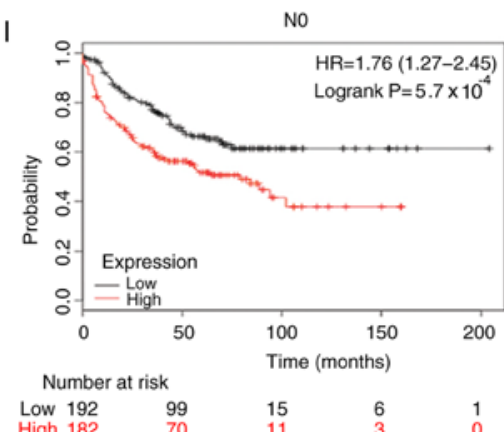

B

First progression

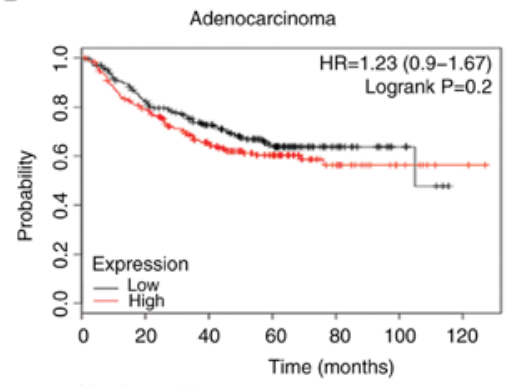

Number at risk

$\begin{array}{lllllll}\text { Low 234 } & 182 & 134 & 81 & 22 & 6 & 0 \\ \text { High 227 } & 171 & 116 & 69 & 22 & 7 & 2\end{array}$

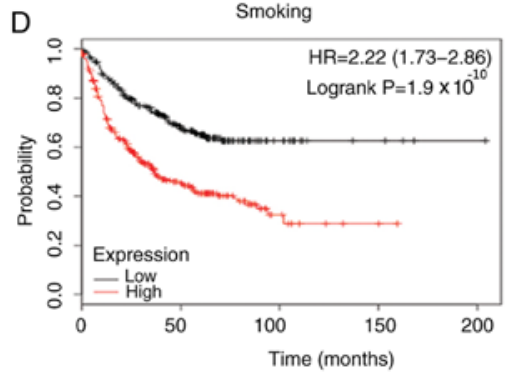

\begin{tabular}{lcccc}
\multicolumn{5}{c}{ Number at risk } \\
Low 302 & 146 & 15 & 4 & 1 \\
High 301 & 84 & 10 & 2 & 0
\end{tabular}

$\mathrm{F} \quad$ Surgical margins negative

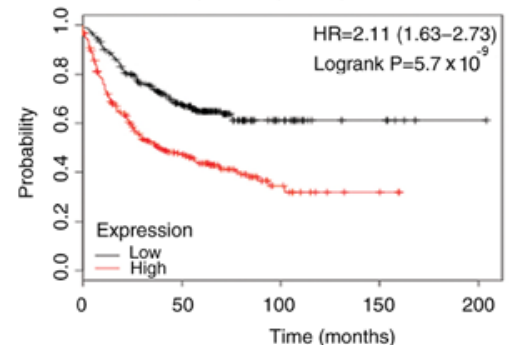

Number at risk

$\begin{array}{ccccc}\text { Low } 281 & 148 & 22 & 6 & 1 \\ \text { High 279 } & 89 & 14 & 3 & 0\end{array}$

$\mathrm{H} \quad$ Male

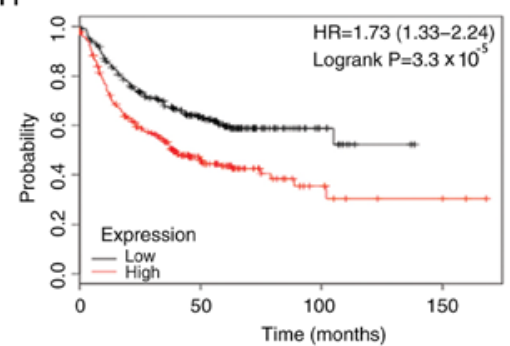

Number at risk

$\begin{array}{rrrr}\text { Low 258 } & 109 & 11 & 0 \\ \text { High 256 } & 68 & 9 & 3\end{array}$

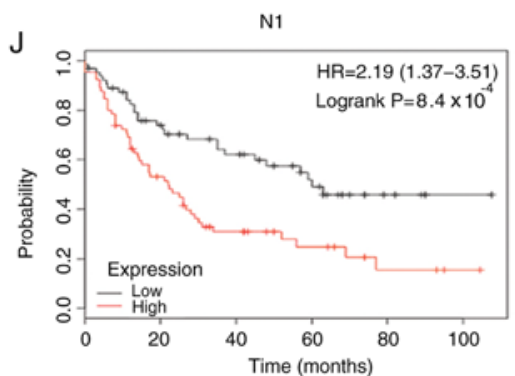

Number at risk

$\begin{array}{lrrrrr}\text { Low } 65 & 41 & 30 & 18 & 4 & 1 \\ \text { High } 65 & 32 & 16 & 8 & 3 & 1\end{array}$

Figure 5. Kaplan-Meier survival curves of patients with lung cancer stratified by expression levels of RPFL3S. Black and red lines indicate patients with low or high RFPL3S expression, respectively. First-progression survival analysis of RFPL3S in lung cancer in (A) all patients, (B) adenocarcinoma, (C) squamous cell carcinoma, (D) smokers, (E) non-smokers, (F) tumor-negative surgical margins, (G) females, (H) males, (I) N0 and (J) N1. 

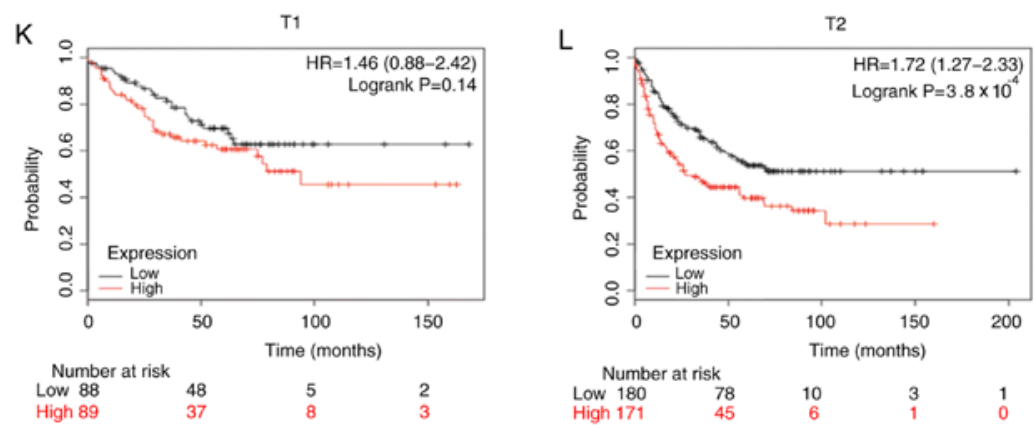

Figure 5. Continued. First-progression survival analysis of RFPL3S in lung cancer in (K) T1 and (L) T2. Statistical significance was calculated using the log-rank test. RFPL3S, RFPL3 antisense.

cancer. The association between patient survival and RFPL3S expression status was analyzed using KM-plotter, according to the expression of RFPL3S. A total of 1,926 patients with lung cancer were used for survival analysis. According to the expression of RFPL3S, the samples were divided into two groups (the low and high expression groups). Kaplan-Meier analysis demonstrated that high RFPL3S expression was associated with poorer overall survival (OS) compared with low RFPL3S expression in all patients with lung cancer [hazard ratio $(\mathrm{HR})=1.38 ; \mathrm{P}=5.1 \times 10^{-7}$; Fig. $\left.3 \mathrm{~A}\right]$. In particular, sub-analysis revealed that higher RFPL3S expression was significantly associated with survival in adenocarcinoma $(\mathrm{HR}=1.37 ; \mathrm{P}=7.9$ $\mathrm{x} 10^{-3}$ Fig. $\left.3 \mathrm{~B}\right)$, but not in squamous cell carcinoma $(\mathrm{HR}=1.14$; $\mathrm{P}=0.28$; Fig. $3 \mathrm{C})$, and associated with stage $1(\mathrm{HR}=1.77$; $\mathrm{P}=3.1 \times 10^{-5}$ Fig. 3I), but not in stage $2(\mathrm{HR}=1.12 ; \mathrm{P}=0.54$; Fig. 3J). High RFPL3S mRNA expression was associated with poorer OS in patients with lung cancer who smoked $(\mathrm{HR}=1.6$; $\mathrm{P}=9.1 \times 10^{-6}$; Fig. 3D), non-smokers $(\mathrm{HR}=2.32 ; \mathrm{P}=0.0052$; Fig. 3E), male patients $(\mathrm{HR}=1.22 ; \mathrm{P}=0.013$; Fig. $3 \mathrm{H})$, female patients $\left(\mathrm{HR}=1.71 ; \mathrm{P}=6.7 \times 10^{-6}\right.$; Fig. $\left.3 \mathrm{G}\right)$ and patients with tumor-negative surgical margins $\left(\mathrm{HR}=2.04 ; \mathrm{P}=2.1 \times 10^{-9}\right.$; Fig. 3F). Subsequently, post-progression survival (PPS) in patients with lung cancer was analyzed (Fig. 4). Notably, patients with increased RFPL3S expression exhibited a shorter PPS than patients with lower RFPL3S expression $(\mathrm{HR}=1.36$; $\mathrm{P}=0.016$; Fig. 4A), which was consistent with OS. Furthermore, increased RFPL3S levels were significantly associated with PPS in patients with tumor-negative surgical margins $(\mathrm{HR}=1.61$; $\mathrm{P}=0.0015$; Fig. 4C), female patients $(\mathrm{HR}=1.76 ; \mathrm{P}=0.0034$; Fig. 4D) and patients not receiving radiotherapy $(\mathrm{HR}=1.72$; $\mathrm{P}=0.018$; Fig. 4F). However, no significant differences were demonstrated among patients with adenocarcinoma $(\mathrm{HR}=1.42$; $\mathrm{P}=0.14$; Fig. 4B), male patients $(\mathrm{HR}=1.2 ; \mathrm{P}=0.3$; Fig. 4E) and patients receiving radiotherapy $(\mathrm{HR}=0.71 ; \mathrm{P}=0.25$; Fig. $4 \mathrm{G})$. The association between RFPL3S expression levels and first progression (FP) was analyzed (Fig. 5). The results revealed that FP of all patients with NSCLC, with increased RFPL3S expression was worse than patients with lower RFPL3S expression $\left(\mathrm{HR}=1.85 ; \mathrm{P}=4.1 \times 10^{-10}\right.$; Fig. $\left.5 \mathrm{~A}\right)$, which was in line with the results of OS and PPS. In addition, the Kaplan-Meier analysis revealed that FP of patients with high RFPL3S expression levels was significantly associated with squamous cell carcinoma ( $\mathrm{HR}=1.62 \mathrm{P}=0.035$; Fig. 5C), smoking $(\mathrm{HR}=2.22$; $\mathrm{P}=1.91 \times 10^{-10}$; Fig. 5D), not smoking $(\mathrm{HR}=1.5 ; \mathrm{P}=0.097$; Fig. 5E), male gender $\left(\mathrm{HR}=1.73 ; \mathrm{P}=3.3 \times 10^{-5}\right.$; Fig. $\left.5 \mathrm{H}\right)$, female gender $\left(\mathrm{HR}=1.99 ; \mathrm{P}=2.9 \times 10^{-6} ;\right.$ Fig. $\left.5 \mathrm{G}\right)$, tumor-negative surgical margins $\left(\mathrm{HR}=2.11 ; \mathrm{P}=5.7 \times 10^{-9} ; \mathrm{Fig} .5 \mathrm{~F}\right), \mathrm{N} 0(\mathrm{HR}=1.76$; $\mathrm{P}=5.7 \times 10^{-4}$; Fig. 5I $)$, N1 (HR=2.19; $\mathrm{P}=8.4 \times 10^{-4} ;$ Fig. 5J) and T2 stage $\left(\mathrm{HR}=1.72 ; \mathrm{P}=3.8 \times 10^{-4} ;\right.$ Fig. $\left.5 \mathrm{~L}\right)$. However, no statistically significant differences were observed for adenocarcinoma $(\mathrm{HR}=1.23 ; \mathrm{P}=0.2$; Fig. $5 \mathrm{~B})$ or $\mathrm{T} 1$ stage $(\mathrm{HR}=1.46 ; \mathrm{P}=0.14$; Fig. 5K). Notably, the results demonstrated that higher RFPL3S mRNA expression was significantly associated with shorter survival, including OS, PPS and FP in patients who had tumor-negative surgical margins.

\section{Discussion}

Lung cancer is a heterogeneous disease that consists of a variety of subtypes with distinct biological and clinical features, and presents the highest prevalence and mortality among all malignancies, primarily due to the development of resistance to targeted therapy and distant metastasis (38-41). It is challenging but rewarding to illustrate the pathogenesis of lung cancer, as well as to develop novel biomarkers and discover effective therapeutic approaches for individual patients.

lncRNAs have been widely recognized as pivotal regulators in a several types of human cancer, and their aberrant expression has also been observed in different tumor tissues (42-44). Furthermore, IncRNAs have been demonstrated to serve as a novel class of diagnostic biomarkers and therapeutic targets in cancer (45-47). Several lncRNAs have been reported to play a critical role in the development of different human tumors $(18,48-52)$, thereby providing a logical framework for understanding the complexities of neoplastic disease (53) and regulated gene expression at different levels. However, the role of lncRNA expression in lung cancer remains unclear. To the best of our knowledge, the present study was the first to investigate the association between RFPL3S expression and the clinicopathological characteristics and prognosis of patients with lung cancer. In the present study, according to the results of the associations between RFPL3S expression levels and clinicopathological characteristics, RFPL3S expression levels may be associated with poorer differentiation, lymph node metastasis, TNM stage and Ki-67 labeling index. A number of previous studies have indicated that all of the above were associated with a worse prognosis when compared with other features (54-56), such as the patients with well differentiation and absence of lymph node metastasis. Although statistically significant 
differences were not observed for the factors associated with the size of the primary tumor, a tendency towards a poorer prognosis was observed in patients with increased RFPL3S expression levels. Oncomine analysis demonstrated increased RFPL3S expression levels in lung cancer compared with a variety of other types of cancer; the results were consistent with data obtained when comparing cancerous and normal tissues. Statistically significant differences were observed in the survival analyses, which demonstrated that increased RFPL3S expression was associated with shorter OS in all patients with lung cancer. Patients with increased RFPL3S expression levels had shorter survival times, which is in line with the results regarding PPS and FP. Notably, patients with a smoking history, which has been thought to be the predominant cause of multiple types of cancer and increases the incidence of lung cancer in the general population, demonstrated the potential of RFPL3S in the poor prognosis of lung cancer (57-61).

RFPL3S is the antisense transcript of the gene RFPL3 that is comprised of four exons and is formed by transcription in the opposite direction to the sense RFPL3 transcript, depending on the structure and position of the splicing sites for RFPL3S (34). A previous study identified $1.2 \mathrm{kB}$ non-coding antisense mRNAs of RFPL3S genes, which cover substantial portions of their sense counterparts, suggesting that RFPL3S is involved in the post-transcriptional regulation of the sense RFPL genes at different spatial and temporal windows, and no apparent Open Reading Frame or repetitive elements could be detected (33). RFPL3, belonging to the RFPL protein family (including RFPL1, RFPL2 and RFPL3) (33), can increase telomerase activity and length (62), and promote the proliferation of tumor cells by regulating the expression of the human telomerase reverse transcriptase (hTERT) gene in NSCLC cells and driving hTERT promoter transcription (63). Epidermal growth factor significantly increased the levels of RFPL 3 and hTERT proteins in NSCLC cells via activation of the MEK signaling pathway, resulting in promoting proliferation (63). In addition, CREB binding protein has been identified to coordinate with RFPL3 to regulate hTERT promoter activity through acetylation to promote lung cancer cell growth (64). However, further research is required to identify the molecular mechanisms that participate in RFPL3S upregulation in lung cancer.

Overall, the present study demonstrated that RFPL3S expression was upregulated and significantly associated with poor prognosis in lung cancer. Therefore, it may act as a potential prognostic biomarker in lung cancer. However, further studies are required to determine the underlying molecular mechanisms that are associated with RFPL3S expression in lung cancer.

\section{Acknowledgements}

Not applicable.

\section{Funding}

The present study was funded by National Natural Science Foundation of China (grant nos. 81402176, 81402093 and 81472296), the Natural Science Foundation of Jiangsu Province, China (grant no. BK20140288), the Science Technology
Project of Suzhou Xiangcheng District (grant nos. XJ201456 and XJ201532), the Livelihood Science and Technology of Soochow (grant nos. SYS201752 and SS2018062), the Industry-University-Research Cooperation, Prospective Joint Research Project of Jiangsu Province (grant no. BY2015039-01), the Science Foundation of The First People's Hospital of Wujiang District, Suzhou (grant nos. 201310 and 201806) and the Project in Science and Education of Wujiang District (grant no. wwk201808).

\section{Availability of data and materials}

The datasets generated and/or analyzed during the present study are available from the corresponding author upon reasonable request. The datasets generated and/or analyzed during the current study are also available in the specified repository and the web links are listed in the Materials and methods.

\section{Authors' contributions}

CC and XY designed the study and wrote the manuscript. FZ collected specimens and patient information, and revised the initial manuscript. ZL and ZQN performed the experiments. THC and HL conducted the statistical analysis. All authors read and approved the final manuscript.

\section{Ethics approval and consent to participate}

The present study was approved by the Ethics Committee of The First People's Hospital of Wujiang District. Written informed consent was obtained from all the patients recruited.

\section{Patient consent for publication}

Not applicable.

\section{Competing interests}

The authors declare that they have no competing interests.

\section{References}

1. Bray F, Ferlay J, Soerjomataram I, Siegel RL, Torre LA and Jemal A: Global cancer statistics 2018: GLOBOCAN estimates of incidence and mortality worldwide for 36 cancers in 185 countries. CA Cancer J Clin 68: 394-424, 2018.

2. Jemal A, Bray F, Center MM, Ferlay J, Ward E and Forman D: Global cancer statistics. CA Cancer J Clin 61: 69-90, 2011.

3. Salem A, Asselin MC, Reymen B, Jackson A, Lambin P, West CML, O'Connor JPB and Faivre-Finn C: Targeting hypoxia to improve non-small cell lung cancer outcome. J Natl Cancer Inst 110, 2018.

4. Lin DD, Shen Y, Qiao S, Liu WW, Zheng L, Wang YN, Cui N, Wang YF, Zhao S and Shi JH: Upregulation of OTUD7B (Cezanne) promotes tumor progression via AKT/VEGF pathway in lung squamous carcinoma and adenocarcinoma. Front Oncol 9: 862, 2019.

5. Wang J, Lu Q, Cai J, Wang Y, Lai X, Qiu Y, Huang Y, Ke Q, Zhang Y, Guan Y, et al: Nestin regulates cellular redox homeostasis in lung cancer through the Keap1-Nrf2 feedback loop. Nat Commun 10: 5043, 2019.

6. Huang N, Guo W, Ren K, Li W, Jiang Y, Sun J, Dai W and Zhao W: LncRNA AFAP1-AS1 supresses miR-139-5p and promotes cell proliferation and chemotherapy resistance of non-small cell lung cancer by competitively upregulating RRM2. Front Oncol 9: $1103,2019$. 
7. Pfannschmidt J, Muley T, Bulzebruck H, Hoffmann $\mathrm{H}$ and Dienemann H: Prognostic assessment after surgical resection for non-small cell lung cancer: Experiences in 2083 patients. Lung Cancer 55: 371-377, 2007.

8. Reungwetwattana T, Weroha SJ and Molina JR: Oncogenic pathways, molecularly targeted therapies, and highlighted clinical trials in non-small-cell lung cancer (NSCLC). Clin Lung Cancer 13: 252-266, 2012.

9. Karuppasamy R, Veerappapillai S, Maiti S, Shin WH and Kihara D: Current progress and future perspectives of polypharmacology: From the view of non-small cell lung cancer. Semin Cancer Biol, Nov 4, 2019 (Epub ahead of print).

10. Hirashima T, Satouchi M, Hida T, Nishio M, Kato T, Sakai H, Imamura F, Kiura K, Okamoto I, Kasahara K, et al: Osimertinib for Japanese patients with T790M-positive advanced non-small-cell lung cancer: A pooled subgroup analysis. Cancer Sci 110: 2884-2893, 2019

11. Balekian AA, Wisnivesky JP and Gould MK: Surgical disparities among patients with stage $\mathrm{i}$ lung cancer in the national lung screening trial. Chest 155: 44-52, 2019.

12. Davis JN, Medbery C, Sharma S, Pablo J, Kimsey F, Perry D, Muacevic A and Mahadevan A: Stereotactic body radiotherapy for centrally located early-stage non-small cell lung cancer or lung metastases from the RSSearch $(\circledR)$ patient registry. Radiat Oncol 10: 113, 2015.

13. ENCODE Project Consortium: An integrated encyclopedia of DNA elements in the human genome. Nature 489: 57-74, 2012.

14. Shaughnessy AF: High false-positive rate with lung cancer screening. Am Fam Physician 96: 128-129, 2017.

15. Belanger AR and Akulian JA: An update on the role of advanced diagnostic bronchoscopy in the evaluation and staging of lung cancer. Ther Adv Respir Dis 11: 211-221, 2017.

16. Jiang M, Huang O, Xie Z, Wu S, Zhang X, Shen A, Liu H, Chen X, Wu J, Lou Y, et al: A novel long non-coding RNA-ARA Adriamycin resistance-associated. Biochem Pharmacol 87: 254-283, 2014.

17. Yan B and Wang Z: Long noncoding RNA: Its physiological and pathological roles. DNA Cell Biol 31 (Suppl 1): S34-S41, 2012.

18. Fang XY, Pan HF, Leng RX and Ye DQ: Long noncoding RNAs: Novel insights into gastric cancer. Cancer Lett 356: 357-366, 2015.

19. Kaikkonen MU, Lam MT and Glass CK: Non-coding RNAs as regulators of gene expression and epigenetics. Cardiovasc Res 90: 430-440, 2011.

20. Li X, Wu Z, Fu X and Han W: Long noncoding RNAs: Insights from biological features and functions to diseases. Med Res Rev 33: 517-553, 2013.

21. Guttman M and Rinn JL: Modular regulatory principles of large non-coding RNAs. Nature 482: 339-346, 2012.

22. Martianov I, Ramadass A, Serra Barros A, Chow N and Akoulitchev A: Repression of the human dihydrofolate reductase gene by a non-coding interfering transcript. Nature 445 666-670, 2007.

23. Gong Z, Zhang S, Zhang W, Huang H, Li Q, Deng H, Ma J, Zhou M, Xiang J, Wu M, et al: Long non-coding RNAs in cancer. Sci China Life Sci 55: 1120-1124, 2012

24. Yu W, Gius D, Onyango P, Muldoon-Jacobs K, Karp J, Feinberg AP and $\mathrm{Cui} \mathrm{H}$ : Epigenetic silencing of tumour suppressor gene p15 by its antisense RNA. Nature 451: 202-206, 2008.

25. Hung T and Chang HY: Long noncoding RNA in genome regulation: Prospects and mechanisms. RNA Biol 7: 582-585, 2010.

26. Satish S, Sourav G, Vaibhav J, Vinod S and Shantanu S: Genome-wide analysis reveals distinct patterns of epigenetic features in long non-coding RNA loci. Nucleic Acids Res 40: 10018-10031, 2012.

27. Volders PJ, Helsens K, Wang X, Menten B, Martens L, Gevaert K, Vandesompele J and Mestdagh P: LNCipedia: A database for annotated human lncRNA transcript sequences and structures. Nucleic Acids Res 41 (Database Issue): D246-D251, 2013.

28. Niazi F and Valadkhan S: Computational analysis of functional long noncoding RNAs reveals lack of peptide-coding capacity and parallels with 3' UTRs. RNA 18: 825-843, 2012.

29. Moran VA, Perera RJ and Khalil AM: Emerging functional and mechanistic paradigms of mammalian long non-coding RNAs Nucleic Acids Res 40: 6391-6400, 2012

30. Gutschner T and Diederichs S: The hallmarks of cancer: A long non-coding RNA point of view. RNA Biol 9: 703-719, 2012.

31. Spizzo R, Almeida MI, Colombatti A and Calin GA: Long non-coding RNAs and cancer: A new frontier of translational research? Oncogene 31: 4577-4587, 2012.
32. Brunner AL, Beck AH, Edris B, Sweeney RT, Zhu SX, Li R, Montgomery K, Varma S, Gilks T, Guo X, et al: Transcriptional profiling of long non-coding RNAs and novel transcribed regions across a diverse panel of archived human cancers. Genome Biol 13: R75, 2012 .

33. Seroussi E, Kedra D, Pan HQ, Peyrard M, Schwartz C, Scambler P, Donnai D, Roe BA and Dumanski JP: Duplications on human chromosome 22 reveal a novel Ret Finger Protein-like gene family with sense and endogenous antisense transcripts. Genome Res 9: 803-814, 1999.

34. Travis WD, Brambilla E, Nicholson AG, Yatabe Y, Austin JHM, Beasley MB, Chirieac LR, Dacic S, Duhig E, Flieder DB, et al: The 2015 world health organization classification of lung tumors: Impact of Genetic, Clinical and radiologic advances since the 2004 classification. J Thorac Oncol 10: 1243-1260, 2015.

35. Anna W and Jacek J: The new TNM classification in lung cancer. Pneumonol Alergol Pol 78: 407-417, 2010 (In Polish).

36. Livak KJ and Schmittgen TD: Analysis of relative gene expression data using real-time quantitative PCR and the 2(-Delta Delta C(T)) method. Methods 25: 402-408, 2001.

37. Lin HY, Zeng, Liang YK, Wei XL and Chen CF: GATA3 and TRPS1 are distinct biomarkers and prognostic factors in breast cancer: Database mining for GATA family members in malignancies. Oncotarget 8: 34750-34761, 2017.

38. Pao W, Miller VA, Politi KA, Riely GJ, Somwar R, Zakowski MF, Kris MG and Varmus H: Acquired resistance of lung adenocarcinomas to gefitinib or erlotinib is associated with a second mutation in the EGFR kinase domain. PLoS Med 2: e73, 2005.

39. Engelman JA, Zejnullahu K, Mitsudomi T, Song Y, Hyland C, Park JO, Lindeman N, Gale CM, Zhao X, Christensen J, et al: MET amplification leads to gefitinib resistance in lung cancer by activating ERBB3 signaling. Science 316: 1039-1043, 2007.

40. Choi YL, Soda M, Yamashita Y, Ueno T, Takashima J, Nakajima T, Yatabe Y, Takeuchi K, Hamada T, Haruta H, et al: EML4-ALK mutations in lung cancer that confer resistance to ALK inhibitors. N Engl J Med 363: 1734-1739, 2010.

41. Mittal V: Epithelial mesenchymal transition in aggressive lung cancers. Adv Exp Med Biol 890: 37-56, 2016.

42. Gupta RA, Shah N, Wang KC, Kim J, Horlings HM, Wong DJ, Tsai MC, Hung T, Argani P, Rinn JL, et al: Long non-coding RNA HOTAIR reprograms chromatin state to promote cancer metastasis. Nature 464: 1071-1076, 2010.

43. Yang F, Bi J, Xue X, Zheng L, Zhi K, Hua J and Fang G: Up-regulated long non-coding RNA H19 contributes to proliferation of gastric cancer cells. FEBS J 279: 3159-3165, 2012.

44. Qi D, Li J, Que B, Su J, Li M, Zhang C, Yang M, Zhou G and Ji W: Long non-coding RNA DBCCR1-003 regulate the expression of DBCCR1 via DNMT1 in bladder cancer. Cancer Cell Int 16: 81, 2016.

45. Qiu MT, Hu JW, Yin R and Xu L: Long noncoding RNA: An emerging paradigm of cancer research. Tumour Biol 34: 613-620, 2013.

46. Sun J, Song Y, Chen X, Zhao J, Gao P, Huang X, Xu H and Wang Z: Novel long non-coding RNA RP11-119F7.4 as a potential biomarker for the development and progression of gastric cancer. Oncol Lett 10: 115-120, 2015.

47. Tian Y, Zheng Y and Dong X: AGAP2-AS1 serves as an oncogenic lncRNA and prognostic biomarker in glioblastoma multiforme. J Cell Biochem 120: 9056-9062, 2019.

48. Kunej T, Obsteter J, Pogacar Z, Horvat S and Calin GA: The decalog of long non-coding RNA involvement in cancer diagnosis and monitoring. Crit Rev Clin Lab Sci 51: 344-357, 2014.

49. Zhang S, Ma H, Zhang D, Xie S, Wang W, Li Q, Lin Z and Wang Y: LncRNA KCNQ1OT1 regulates proliferation and cisplatin resistance in tongue cancer via miR-211-5p mediated Ezrin/Fak/Src signaling. Cell Death Dis 9: 742, 2018.

50. Lu Z, Xiao Z, Liu F, Cui M, Li W, Yang Z, Li J, Ye L and Zhang X: Long non-coding RNA HULC promotes tumor angiogenesis in liver cancer by up-regulating sphingosine kinase 1 (SPHK1). Oncotarget 7: 241-254, 2016.

51. Liang H, Tong Y, Yue H, Jiang H, Wang C, You T, Zhao X, Shan H, Yang R, Yang L, et al: LncRNA PTAR promotes EMT and invasion-metastasis in serous ovarian cancer by competitively binding miR-101-3p to regulate ZEB1 expression. Mol Cancer 17: 119, 2018.

52. Su M, Xiao Y, Ma J, Cao D, Zhou Y, Wang H, Liao Q and Wang W: Long non-coding RNAs in esophageal cancer: Molecular mechanisms, functions, and potential applications. J Hematol Oncol 11: 118, 2018 
53. Hanahan D and Weinberg RA: Hallmarks of cancer: The next generation. Cell 144: 646-674, 2011.

54. Barletta JA, Yeap BY and Chirieac LR: Prognostic significance of grading in lung adenocarcinoma. Cancer 116: 659-669, 2010.

55. Tabata K, Tanaka T, Hayashi T, Hori T, Nunomura S, Yonezawa S and Fukuoka J: Ki-67 is a strong prognostic marker of non-small cell lung cancer when tissue heterogeneity is considered. BMC Clin Pathol 14: 23, 2014.

56. Woodard GA, Jones KD and Jablons DM: Lung cancer staging and prognosis. Cancer Treat Res 170: 47-75, 2016.

57. Zhang H, Cai B: The impact of tobacco on lung health in China. Respirology 8: 17-21, 2003.

58. Levine AJ, Momand J and Finlay CA: The p53 tumour suppressor gene. Nature 351: 453-456, 1991.

59. Fujino M, Dosaka-Akita H, Harada M, Hiroumi H, Kinoshita I, Akie K and Kawakami Y: Prognostic significance of p53 and ras p21 expression in nonsmall cell lung cancer. Cancer 76: 2457-2463, 1995.

60. Pfeifer GP, Denissenko MF, Olivier M, Tretyakova N, Hecht SS and Hainaut P: Tobacco smoke carcinogens, DNA damage and p53 mutations in smoking-associated cancers. Oncogene 21: 7435-7451, 2002.

61. The Medical Research Council: Tobacco smoking and lung cancer. Br Med J 1: 1523-1524, 1957.
62. Chen W, Lu J, Qin Y, Wang J, Tian Y, Shi D, Wang S, Xiao Y, Dai M, Liu L, et al: Ret finger protein-like 3 promotes tumor cell growth by activating telomerase reverse transcriptase expression in human lung cancer cells. Oncotarget 5: 11909-11923, 2014.

63. Lin C, Qin Y, Zhang H, Gao MY and Wang YF: EGF upregulates RFPL3 and hTERT via the MEK signaling pathway in nonsmall cell lung cancer cells. Oncol Rep 40: 29-38, 2018.

64. Yu Q, Wangbing C, Yao X, Yu W, Cai X, Dai M, Xu T, Huang W, Guo W, Deng W and Wu T: RFPL3 and CBP synergistically upregulate hTERT activity and promote lung cancer growth. Oncotarget 6: 27130-27145, 2015.

This work is licensed under a Creative Commons Attribution-NonCommercial-NoDerivatives 4.0 International (CC BY-NC-ND 4.0) License. 